\title{
Solving Parameter Identification of Nonlinear Problems by Artificial Bee Colony Algorithm
}

\author{
S. Talatahari, ${ }^{1}$ H. Mohaggeg, ${ }^{1}$ Kh. Najafi, ${ }^{2}$ and A. Manafzadeh $^{2}$ \\ ${ }^{1}$ Department of Civil Engineering, University of Tabriz, Tabriz, Iran \\ ${ }^{2}$ Department of Civil Engineering, Azad University of Mahabad, Mahabad, Iran
}

Correspondence should be addressed to S. Talatahari; siamak.talat@gmail.com

Received 19 February 2014; Revised 7 June 2014; Accepted 11 June 2014; Published 13 July 2014

Academic Editor: Fei Kang

Copyright (C) 2014 S. Talatahari et al. This is an open access article distributed under the Creative Commons Attribution License, which permits unrestricted use, distribution, and reproduction in any medium, provided the original work is properly cited.

\begin{abstract}
A new optimization method based on artificial bee colony $(A B C)$ algorithm is presented for solving parameter identification problems. The $\mathrm{ABC}$ algorithm as a swarm intelligent optimization algorithm is inspired by honey bee foraging. In this paper, for the first time, the ABC method is developed to determine the optimum parameters of Bouc-Wen hysteretic systems. The proposed method exhibits efficiency, robustness, and insensitivity to noise-corrupted data. The results of the ABC are compared with those other optimization algorithms from the literature to show the efficiency of this technique for solving parameter identification problems.
\end{abstract}

\section{Introduction}

A process of finding a feasible solution for a problem containing an objective function to be minimized and some restrictions to be satisfied is defined as the optimization. In general, there are two types for solving optimization problems: classic or mathematic-based approaches and metaheuristic methods. Due to some difficulties in using mathematical approaches, metaheuristic optimization algorithms have been widely utilized to solve parameter identification problems in which the aim is to minimize the differences between real and numerical data and identify the best set of values for the unknown parameters [1]. Table 1 reviews several examples of the parameters identification problems [2].

Among the different identification problems above, due to its highly nonlinear nature, identification of Bouc-Wen systems constitutes a challenging problem. The Bouc-Wen model is a smooth endochronic model that is often used to describe hysteretic phenomena. It was introduced by Bouc [3] and extended by Wen [4], who demonstrated its versatility by producing a variety of hysteretic patterns. There are different methods developed to solve this difficult problem, such as Gauss-Newton [5], modified Gauss-Newton [6], least squares [7], simplex [8], Levenberg-Marquardt [8, 9], extended Kalman filters $[8,10]$, reduced gradient methods [8], genetic algorithms (GAs) [11], real-coded GAs [12], differential evolution [13, 14], adaptive laws [15], hybrid evolutionary algorithm [16], particle swarm optimization [17], simulated annealing [18], adaptive charged system search [1], and a hybrid developed algorithm based on particle swarm optimization and big bang-big crunch algorithms [19].

In this paper, we developed artificial bee colony $(\mathrm{ABC})$ algorithm [20,21] to solve parameter identification of BoucWen model for the first time. The rest of the paper is organized as follows. Section 2 presents the formulation of the parameter identification problem. The framework of the ABC algorithm is described in Section 3. Numerical examples are presented in Section 4 and finally Section 5 concludes the paper.

\section{Problem Formulation}

2.1. Standard Bouc-Wen Model. For the standard Bouc-Wen model, nonlinear force of damper is calculated as follows:

$$
F=\varphi z+c_{0} \dot{x}+k_{0}\left(x-x_{0}\right)
$$


TABLE 1: A review on several examples of the parameters identification problems.

\begin{tabular}{|c|c|c|c|}
\hline Description of the work & Studied structure & Research field & Authors \\
\hline $\begin{array}{l}\text { Estimation bridge's supports conditions and material } \\
\text { properties }\end{array}$ & Bridge & STR & Robert-Nicoud et al. [22] \\
\hline $\begin{array}{l}\text { Estimation of the reliability of bridge using environmental } \\
\text { monitoring data (temperature and wind loads) }\end{array}$ & Bridge model & STR & Catbas et al. [23] \\
\hline
\end{tabular}

Parameter identification of Bouc-Wen model for MR fluid dampers using adaptive charged system search optimization and a hybrid algorithm

MR fluid dampers $\quad$ STR Talatahari et al. $[1,19]$

Use of deflections, rotation, and strain to identify the best model of identification of geotechnical parameters combining a metaheuristic algorithm (particle swarm optimization), support machine vector, and numerical analysis to integrate nonlinear relationship between displacement and mechanical properties

Identification of the water infiltration in an unsaturated soil column by using a modified particle swarm optimization algorithm

Soil parameters

Soil parameters

Identification of several geotechnical parameters on two cases: an oedometer test and an application on a natural slope

Identification of equivalent stiffnesses of a structure that mimics soil-structure interaction parameters by inverse analysis using the particle swarm optimization algorithm

Identification of Mohr-Coulomb parameters combining displacements data, the genetic algorithm, and a Plaxis model

Application of the inverse analysis to modify excavation project in progress using displacement data of the buildings around the site

STR: structure; SSI: soil-structure interaction; GEO: geotechnical.

where $\varphi$ is the Bouc-Wen model parameter related to the ratio of MR material's final and initial yield stress and $k_{0}$ and $c_{0}$ are spring stiffness and dashpot damping coefficient, respectively, and $z$ is the hysteretic deformation of the model which is defined as

$$
\dot{z}=-\gamma|\dot{x}| z|z|^{n-1}-\beta \dot{x}|z|^{n}+A \dot{x},
$$

in which $A, \beta$, and $\gamma$ are the Bouc-Wen model shape parameters.

2.2. Modified Bouc-Wen Model. In this case, the nonlinear force is calculated as

$$
\begin{aligned}
F & =\varphi z+c_{0}(\dot{x}-\dot{y})+k_{0}(x-y)+k_{1}\left(x-x_{0}\right) \\
& =c_{1} \dot{y}+k_{1}\left(x-x_{0}\right) .
\end{aligned}
$$

Here, hysteretic displacement $z$ is given by

$$
\dot{z}=-\gamma|\dot{x}-\dot{y}| z|z|^{n-1}-\beta(\dot{x}-\dot{y})|z|^{n}+A(\dot{x}-\dot{y})
$$

in which $\dot{y}$ is defined by the following equation:

$$
\dot{y}=\frac{1}{\left(c_{0}+c_{1}\right)}\left\{\alpha z+c_{0} \dot{x}+k_{0}(x-y)\right\} .
$$

2.3. Statement of the Optimization Problem. The mean square error (MSE) of the predicted response time history $\widehat{f}\left(t_{i} \mid \mathbf{p}\right)$ (for any obtained parameters' vector $\mathbf{p}$ ) in comparison with the experimentally obtained response history $f\left(t_{i}\right)$ at each time step $t_{i}$ is usually considered as the objective function to be minimized as

$$
\mathrm{OF}(\mathbf{p})=\frac{\sum_{i=1}^{N}\left(f\left(t_{i}\right)-\widehat{f}\left(t_{i} \mid \mathbf{p}\right)\right)^{2}}{N \sigma_{f}^{2}},
$$

in which $\mathbf{p}$ is the vector of model's parameters; $\sigma_{f}^{2}$ is the variance of experimental response time history; $\sum$ represents the summation of its subsequent term ( $N$ discrete values); and $N$ is the number of experimental data employed in the optimization process. It should be noticed that the optimization problem involves the minimization of the objective 
function when the parameters vector is varied between the following side constraints:

$$
\mathbf{p}_{\min } \leq \mathbf{p} \leq \mathbf{p}_{\max },
$$

where $\mathbf{p}_{\min }$ and $\mathbf{p}_{\max }$ are the vectors which include the lower and upper bounds of the model parameters, respectively.

\section{Artificial Bee Colony (ABC) Algorithm}

The $\mathrm{ABC}$ algorithm as a swarm intelligent optimization algorithm is inspired by honey bee foraging. This section reviews the framework of the algorithm briefly.

3.1. General Aspects [30]. The ABC algorithm utilizes a population of artificial bees. Their locations are considered as foods positions and modified with the time by discovering some places with high nectars. In $\mathrm{ABC}$ system, artificial bees fly around in a multidimensional search space and some (employed and onlooker bees) choose food sources depending on their experience and their nest mates and adjust their positions. Some (scouts) fly and choose the food sources randomly without using experience. If the nectar amount of a new source is higher than that of the previous one in their memory, they memorize the new position and forget the previous one. Thus, ABC system combines local search methods, carried out by employed and onlooker bees, with global search methods, managed by onlookers and scouts, attempting to balance the exploration and exploitation processes. This model that leads to the emergence of collective intelligence of honeybee swarms consists of three essential components, food sources, employed foragers, and unemployed foragers, and defines two leading modes of the honeybee colony behavior: requirement of a food source and abandonment of a source. The main components of this model are as follows.

(1) Food Sources. In order to select a food source, a forager bee evaluates several properties related to the food source such as its closeness to the hive, richness of the energy, taste of its nectar, and the ease or difficulty of extracting this energy. For the simplicity, the quality of a food source can be represented by only one quantity although it depends on various parameters mentioned above.

(2) Employed Foragers. An employed forager carries information about her specific source and shares it with other bees waiting in the hive. The information includes the distance, the direction, and the profitability of the food source.

(3) Unemployed Foragers. A forager bee that looks for a food source to exploit is called unemployed. It can be either a scout who searches the environment randomly or an onlooker who tries to find a food source by means of the information given by the employed bee.

3.2. The Algorithm. Figure 1 presents the flowchart of the artificial bee colony algorithm. Each iteration of the search process consists of three steps as follows (after initialization stage) [30]: (i) placing the employed bees onto the food sources and calculating their nectar amounts;

(ii) placing the onlookers onto the food sources and calculating the nectar amounts;

(iii) determining the scout bees and placing them onto the randomly determined food sources.

In the $\mathrm{ABC}$ algorithm, the first half of the colony consists of the employed artificial bees and the second half includes the onlookers. In this algorithm, for every food source, there is only one employed bee. In other words, the number of employed bees is equal to the number of food sources around the hive. The employed bee whose food source has been abandoned becomes a scout.

The position of a food source represents a possible solution to the considered optimization problem and the nectar amount of the food source corresponds to the quality or fitness of the associated solution. The number of the employed bees or onlooker bees is equal to the number of solutions in the population. In the first step, the ABC algorithm generates randomly distributed predefined number of initial population, $P$ (position of the food sources), of $S N$ populations. Each position of the food source, $x_{i j k}$, is three-dimensional in nature with $i=1,2, \ldots, S N ; j=$ $1,2, \ldots, D$; and $k=1,2, \ldots, V$, where $D$ is the dimension of each variable and $V$ is the number of variables in the objective function. After initialization, the population of the positions (solutions) is subjected to the repeated cycles, $C=$ $1,2, \ldots$, MaxIter (maximum iteration number), of the search process of the employed bees, onlooker bees, and scout bees. An employed bee produces a modification on the solution in its memory depending on the local information and tests the nectar amount (fitness value) of the new food source (new solution). Provided that the nectar amount of the new source is higher than that of the previous one, the bee memorizes the new position and forgets the old one. Otherwise, it keeps the position of the previous source in its memory. When all the employed bees complete the search process, they share the nectar information of the food sources and their position information with the onlooker bees in the dance area. An onlooker bee evaluates the nectar information taken from all the employed bees and selects a food source with a probability related to its nectar amount. As in the case of an employed bee, the onlooker bee produces a modification on the position in its memory and checks the nectar amount of the candidate source. If its nectar amount is higher than that of the previous one, the onlooker bee memorizes the new position and forgets the old one.

\section{Numerical Investigation}

The standard Bouc-Wen model needs twelve parameters $\left(\alpha_{a}\right.$, $\left.\alpha_{b}, c_{0 a}, c_{0 b}, k_{0 a}, k_{0 b}, x_{0}, \gamma, \beta, A, n, \eta\right)$, while 14 ones $\left(\alpha_{a}\right.$, $\left.\alpha_{b}, c_{0 a}, c_{0 b}, c_{1 a}, c_{1 b}, k_{0}, k_{1}, x_{0}, \gamma, \beta, A, n, \eta\right)$ are sufficient for modified version. Two numerical examples for standard and modified Bouc-Wen models of dampers are optimized utilizing the proposed ABC method. Table 2 presents the used experimental data [29]. The input control signal, piston 


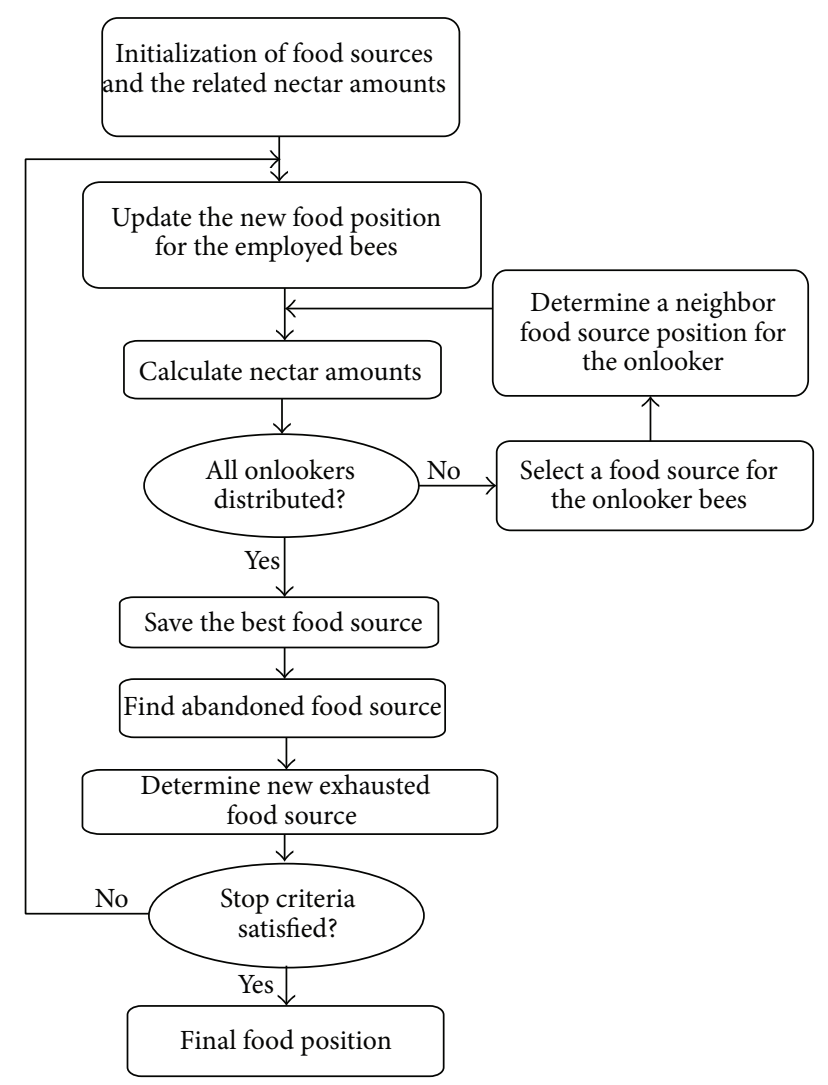

FIgURE 1: Flowchart of the ABC algorithm.

movement, and response of the MR damper for the standard Bouc-Wen model are determined from numerical simulation of a 3-storey building case study in [31], in which a direct modulating controller was designed in order to control the dampers' force and mitigation of structural responses due to the El Centro earthquake, while for the modified model, it is determined from numerical simulation of an 11-storey example subjected to the El Centro earthquake in [32] controlled using the clipped-optimal control algorithm. The sample displacement and control voltage history applied simultaneously to the MR damper and the whole data set is considered in the optimization process.

It has been corroborated that simple Bouc-Wen model suffers from parameter redundancy and multiple sets of parameters could be the solution of a specified problem resulting in similar fairly low MSE [1]. However, it should be included that to conduct a full survey on effectiveness of the algorithm, the redundant version of simple Bouc-Wen model is considered in the current study which contains one more parameter to be specified.

The algorithms were implemented using MATLAB to run on a computer with an Intel Core i5 CPU, $2.53 \mathrm{GHz}$ processor, and $3.00 \mathrm{~GB}$ RAM. The standard PSO and $\mathrm{BB}$ $\mathrm{BC}$ methods [19] as well as the $\mathrm{ABC}$ algorithm are utilized to solve the optimum parameters of Bouc-Wen models. We use different random seeds in starting each run to perform a strong statistical study. The number of independent runs is set
TABLE 2: Parameters of Bouc-Wen models for a $1000 \mathrm{kN}$ MR damper [29].

\begin{tabular}{lccc}
\hline Parameter & Unit & $\begin{array}{c}\text { Standard B-W } \\
\text { model values } \\
(9 \text { parameters })\end{array}$ & $\begin{array}{c}\text { Modified B-W } \\
\text { model values } \\
(13 \text { parameters })\end{array}$ \\
\hline$x_{0}$ & $\mathrm{~m}$ & - & - \\
$\gamma$ & $\mathrm{m}^{-2}$ & 141 & 164 \\
$\beta$ & $\mathrm{m}^{-2}$ & 141 & 164 \\
$A$ & - & 2075 & 1107.2 \\
$n$ & - & 2 & 2 \\
$\alpha_{a}$ & $\mathrm{kN} / \mathrm{m}$ & 26 & 46.2 \\
$\alpha_{b}$ & $\mathrm{kN} / \mathrm{m} / \mathrm{V}$ & 29.1 & 41.2 \\
$c_{0 a}$ & $\mathrm{kN} \cdot \mathrm{s} / \mathrm{m}$ & 105.4 & 110 \\
$c_{0 b}$ & $\mathrm{kN} \cdot \mathrm{s} / \mathrm{m} / \mathrm{V}$ & 131.6 & 114.3 \\
$c_{1 a}$ & $\mathrm{kN} \cdot \mathrm{s} / \mathrm{m}$ & - & 8359.2 \\
$c_{1 b}$ & $\mathrm{kN} \cdot \mathrm{s} / \mathrm{m} / \mathrm{V}$ & - & 7482.9 \\
$k_{0}$ & $\mathrm{kN} / \mathrm{m}$ & - & 0.002 \\
$k_{1}$ & $\mathrm{kN} / \mathrm{m}$ & - & 0.0097 \\
$\eta$ & $\mathrm{s}-1$ & 100 & 100 \\
\hline
\end{tabular}

to 20 for each scenario in this study. The initial points for each run are changed and it is between lower and upper bounds. The obtained results and the related MSE values for standard and modified Bouc-Wen model are collected in Tables 3 and 4 , respectively. Table 3 shows that the standard PSO and BBBC optimization somehow fail to find the optimal parameters as the margin of errors of parameters rises up to $99.84 \%$ for PSO and $61.21 \%$ for BB-BC [19]. The maximum error for the $\mathrm{ABC}$ method is only $17.20 \%$ which is smaller than the results of the other ones. Furthermore, the amount of the MSE for the new method is $1.34 E-03$ which is outweighing its counterparts with 0.0515 and 0.0137 for PSO and BB-BC, respectively.

The achieved results for the modified Bouc-Wen model (Table 4) also completely demonstrate that the proposed method outperforms those of the standard PSO and BB-BC [19]. In this case, the measured MSE value is 5.71E-04 which is far more less than corresponding values for the PSO and BB-BC.

\section{Conclusion}

The artificial bee colony (ABC) algorithm, based on mimicking the food foraging behavior of honeybee swarms, is developed to solve parameter identification of nonlinear problems. A parameter identification task can be formulated as an optimization problem where the objective is to obtain a set of parameters for a model that minimize the prediction error between the measured plant outputs and the model outputs. The classical common parameter identification approaches, such as the recursive least squares method and autoregressive exogenous method, are substantially analytical and based on a mathematical derivation of the system's model. As an alternative to these methods, metaheuristic algorithms are relatively promising approaches, and a little knowledge 
TABLE 3: Parameter sets found for standard B-W model and MSE report.

\begin{tabular}{|c|c|c|c|c|c|c|c|}
\hline & & & & & & & \\
\hline & & Value & Error (\%) & Value & Error (\%) & Value & Error (\%) \\
\hline$x_{0}$ & $\mathrm{~m}$ & - & - & - & - & - & - \\
\hline$\gamma$ & $\mathrm{m}^{-2}$ & 264.42 & 87.53 & 138.31 & 1.90 & 165.26 & 17.20 \\
\hline$\beta$ & $\mathrm{m}^{-2}$ & 220.46 & 56.36 & 147.71 & 4.76 & 155.75 & 10.46 \\
\hline$A$ & - & 2817.66 & 35.79 & 2431.44 & 17.18 & 1945.75 & 6.23 \\
\hline$n$ & - & 4.00 & 99.84 & 2.56 & 28.01 & 1.970 & 1.48 \\
\hline$\alpha_{a}$ & $\mathrm{kN} / \mathrm{m}$ & 37.30 & 43.45 & 25.17 & 3.21 & 26.67 & 2.58 \\
\hline$\alpha_{b}$ & $\mathrm{kN} / \mathrm{m} / \mathrm{V}$ & 30.59 & 5.12 & 29.39 & 1.00 & 30.209 & 3.81 \\
\hline$c_{0 a}$ & $\mathrm{kN} \cdot \mathrm{s} / \mathrm{m}$ & 195.34 & 85.33 & 169.91 & 61.21 & 105.19 & 0.20 \\
\hline$c_{0 b}$ & $\mathrm{kN} \cdot \mathrm{s} / \mathrm{m} / \mathrm{V}$ & 252.31 & 91.73 & 170.14 & 29.28 & 131.09 & 0.38 \\
\hline$\eta$ & $\mathrm{s}^{-1}$ & 122.92 & 22.92 & 147.28 & 47.28 & 165.26 & 0.31 \\
\hline & response & & & & & & \\
\hline
\end{tabular}

TABle 4: Parameter sets found for modified B-W model and MSE report.

\begin{tabular}{|c|c|c|c|c|c|c|c|}
\hline & & & & & & & \\
\hline & & Value & Error (\%) & Value & Error (\%) & Value & Error (\%) \\
\hline$x_{0}$ & $\mathrm{~m}$ & - & - & - & - & - & - \\
\hline$\gamma$ & $\mathrm{m}^{-2}$ & 160.10 & 2.38 & 176.90 & 7.87 & 156.91 & 4.32 \\
\hline$\beta$ & $\mathrm{m}^{-2}$ & 162.72 & 0.78 & 198.38 & 20.96 & 159.27 & 2.88 \\
\hline$A$ & - & 1296.01 & 17.05 & 1107.59 & 0.04 & 1207.15 & 9.03 \\
\hline$n$ & - & 2.10 & 4.95 & 2.05 & 2.41 & 1.92 & 3.83 \\
\hline$\alpha_{a}$ & $\mathrm{kN} / \mathrm{m}$ & 47.94 & 3.76 & 51.44 & 11.35 & 46.77 & 1.25 \\
\hline$\alpha_{b}$ & $\mathrm{kN} / \mathrm{m} / \mathrm{V}$ & 41.43 & 0.55 & 42.25 & 2.55 & 38.71 & 6.03 \\
\hline$c_{0 a}$ & $\mathrm{kN} \cdot \mathrm{s} / \mathrm{m}$ & 111.02 & 0.92 & 115.53 & 5.03 & 109.63 & 0.33 \\
\hline$c_{0 b}$ & $\mathrm{kN} \cdot \mathrm{s} / \mathrm{m} / \mathrm{V}$ & 115.55 & 1.10 & 139.79 & 22.30 & 115.55 & 1.09 \\
\hline$c_{1 a}$ & $\mathrm{kN} \cdot \mathrm{s} / \mathrm{m}$ & 8488.77 & 1.55 & 10313.72 & 23.38 & 8561.32 & 2.42 \\
\hline$c_{1 b}$ & $\mathrm{kN} \cdot \mathrm{s} / \mathrm{m} / \mathrm{V}$ & 7603.31 & 1.61 & 8499.79 & 13.59 & 7556.57 & 0.98 \\
\hline$k_{0}$ & $\mathrm{kN} / \mathrm{m}$ & 0.0021 & 5.12 & 0.0021 & 3.59 & 0.0019 & 1.43 \\
\hline$k_{1}$ & $\mathrm{kN} / \mathrm{m}$ & 0.0103 & 5.80 & 0.0104 & 6.76 & 0.0100 & 3.13 \\
\hline$\eta$ & $\mathrm{s}^{-1}$ & 111.05 & 11.05 & 104.11 & 4.11 & 100.31 & 0.31 \\
\hline & response & & & & & & \\
\hline
\end{tabular}

about the problem is sufficient for finding the approximate results. In this paper, artificial bee colony as one of the efficient metaheuristics is considered to find two series of realistic Bouc-Wen model parameters containing standard and modified models. Simulation results demonstrate that the proposed method has good performance compared to the PSO and BB-BC algorithms.

\section{Conflict of Interests}

The authors declare that there is no conflict of interests regarding the publication of this paper.

\section{References}

[1] S. Talatahari, A. Kaveh, and N. Mohajer Rahbari, "Parameter identification of Bouc-Wen model for MR fluid dampers using adaptive charged system search optimization," Journal of Mechanical Science and Technology, vol. 26, no. 8, pp. 25232534, 2012.
[2] M. Fontan, A. Ndiaye, D. Breysse, F. Bos, and C. Fernandez, "Soil-structure interaction: parameters identification using particle swarm optimization," Computers and Structures, vol. 89, no. 17-18, pp. 1602-1614, 2011.

[3] R. Bouc, "Forced vibration of mechanical systems with hysteresis," in Proceedings of the 4th Conference on Non-Linear Oscillation, Prague, Czech Republic, 1967.

[4] Y. Wen, "Method for random vibration of hysteretic systems," ASCE Journal of Engineering Mechanics Division, vol. 102, no. 2, pp. 249-263, 1976.

[5] M. Yar and J. K. Hammond, "Parameter estimation for hysteretic systems," Journal of Sound and Vibration, vol. 117, no. 1, pp. 161-172, 1987.

[6] S. K. Kunnath, J. B. Mander, and L. Fang, "Parameter identification for degrading and pinched hysteretic structural concrete systems," Engineering Structures, vol. 19, no. 3, pp. 224-232, 1997.

[7] R. H. Sues, S. T. Mau, and Y.-K. Wen, "System identification of degrading hysteretic restoring forces," Journal of Engineering Mechanics, vol. 114, no. 5, pp. 833-846, 1988. 
[8] H. Zhang, G. C. Foliente, Y. Yang, and F. Ma, "Parameter identification of inelastic structures under dynamic loads," Earthquake Engineering \& Structural Dynamics, vol. 31, no. 5, pp. 1113-1130, 2002.

[9] Y. Q. Ni, J. M. Ko, and C. W. Wong, "Identification of nonlinear hysteretic isolators from periodic vibration tests," Journal of Sound and Vibration, vol. 217, no. 4, pp. 737-756, 1998.

[10] L. Jeen-Shang and Z. Yigong, "Nonlinear structural identification using extended kalman filter," Computers \& Structures, vol. 52, no. 4, pp. 757-764, 1994.

[11] N. M. Kwok, Q. P. Ha, M. T. Nguyen, J. Li, and B. Samali, "BoucWen model parameter identification for a MR fluid damper using computationally efficient GA," ISA Transactions, vol. 46, no. 2, pp. 167-179, 2007.

[12] J.-L. Ha, Y.-S. Kung, R.-F. Fung, and S.-C. Hsien, "A comparison of fitness functions for the identification of a piezoelectric hysteretic actuator based on the real-coded genetic algorithm," Sensors and Actuators A: Physical, vol. 132, no. 2, pp. 643-650, 2006.

[13] A. Kyprianou, K. Worden, and M. Panet, "Identification of hysteretic systems using the differential evolution algorithm," Journal of Sound and Vibration, vol. 248, no. 2, pp. 289-314, 2001.

[14] F. Ma, C. H. Ng, and N. Ajavakom, "On system identification and response prediction of degrading structures," Structural Control and Health Monitoring, vol. 13, no. 1, pp. 347-364, 2006.

[15] J.-L. Ha, R.-F. Fung, and C.-S. Yang, "Hysteresis identification and dynamic responses of the impact drive mechanism," Journal of Sound and Vibration, vol. 283, no. 3-5, pp. 943-956, 2005.

[16] A. E. Charalampakis and V. K. Koumousis, "Identification of Bouc-Wen hysteretic systems by a hybrid evolutionary algorithm," Journal of Sound and Vibration, vol. 314, no. 3-5, pp. 571585, 2008.

[17] A. E. Charalampakis and C. K. Dimou, "Identification of BoucWen hysteretic systems using particle swarm optimization," Computers \& Structures, vol. 88, no. 21-22, pp. 1197-1205, 2010.

[18] P. Liu, H. Liu, J. Teng, and T. Cao, "Parameters identification for smart dampers based on simulated annealing and genetic algorithm," in Proceedings of the IEEE International Conference on Mechatronics and Automation (ICMA '06), pp. 2199-2204, Luoyang, China, June 2006.

[19] S. Talatahari, N. M. Rahbari, and A. Kaveh, "A new hybrid optimization algorithm for recognition of hysteretic non-linear systems," KSCE Journal of Civil Engineering, vol. 17, no. 5, pp. 1099-1108, 2013.

[20] B. Basturk and D. Karaboga, "An artificial bee colony (ABC) algorithm for numerical function optimization," in Proceedings of the IEEE Swarm Intelligence Symposium, Indianapolis, Ind, USA, 2006.

[21] D. Karaboga and B. Basturk, "Artificial Bee Colony (ABC) optimization algorithm for solving constrained optimization problems," in Foundations of Fuzzy Logic and Soft Computing, vol. 4529 of Lecture Notes in Computer Science, pp. 789-798, Springer, Berlin, Germany, 2007.

[22] Y. Robert-Nicoud, B. Raphael, O. Burdet, and I. F. C. Smith, "Model identification of bridges using measurement data," Computer-Aided Civil and Infrastructure Engineering, vol. 20, no. 2, pp. 118-131, 2005.

[23] F. N. Catbas, M. Susoy, and D. M. Frangopol, "Structural health monitoring and reliability estimation: long span truss bridge application with environmental monitoring data," Engineering Structures, vol. 30, no. 9, pp. 2347-2359, 2008.
[24] H. B. Zhao and S. Yin, "Geomechanical parameters identification by particle swarm optimization and support vector machine," Applied Mathematical Modelling, vol. 33, no. 10, pp. 3997-4012, 2009.

[25] Y. Zhang, D. Gallipoli, and C. E. Augarde, "Simulation-based calibration of geotechnical parameters using parallel hybrid moving boundary particle swarm optimization," Computers and Geotechnics, vol. 36, no. 4, pp. 604-615, 2009.

[26] J. Meier, W. Schaedler, L. Borgatti, A. Corsini, and T. Schanz, "Inverse parameter identification technique using PSO algorithm applied to geotechnical modeling," Journal of Artificial Evolution and Applications, vol. 2008, Article ID 574613, 14 pages, 2008.

[27] S. Levasseur, Y. Malécot, M. Boulon, and E. Flavigny, "Soil parameter identification using a genetic algorithm," International Journal for Numerical and Analytical Methods in Geomechanics, vol. 32, no. 2, pp. 189-213, 2008.

[28] P. Schmitt and F. Schlosser, "La méthode observationnelle: du suivi géotechnique au dimensionnement interactif," Travaux, Sols et Fondations, vol. 844, pp. 99-106, 2007.

[29] H.-J. Jung, B. F. Spencer Jr., and I.-W. Lee, "Control of seismically excited cable-stayed bridge employing magnetorheological fluid dampers," Journal of Structural Engineering, vol. 129, no. 7, pp. 873-883, 2003.

[30] S. Talatahari, M. Nouri, and F. Tadbiri, "Optimization of skeletal structures using artificial bee colony algorithm," International Journal of Optimization in Civil Engineering, vol. 2, no. 4, pp. 557-571, 2012.

[31] B. F. Azar, N. M. Rahbari, and S. Talatahari, "Seismic mitigation of tall buildings using magnetorheological dampers," Asian Journal of Civil Engineering, vol. 12, no. 5, pp. 637-649, 2011.

[32] S. J. Dyke and B. F. Spencer Jr., "A comparison of semiactive control strategies for the MR damper," in Proceedings of the IASTED International Conference on Intelligent Information Systems (IIS '97), pp. 580-584, Grand Bahama Island, Bahamas, 1997. 


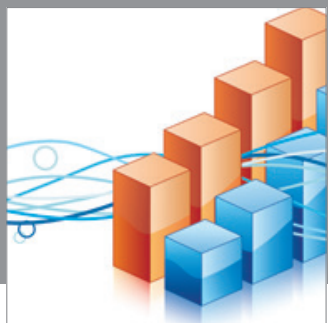

Advances in

Operations Research

mansans

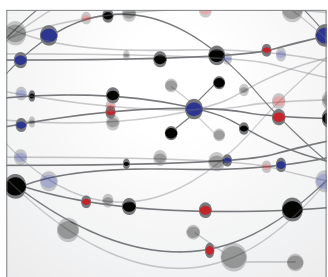

The Scientific World Journal
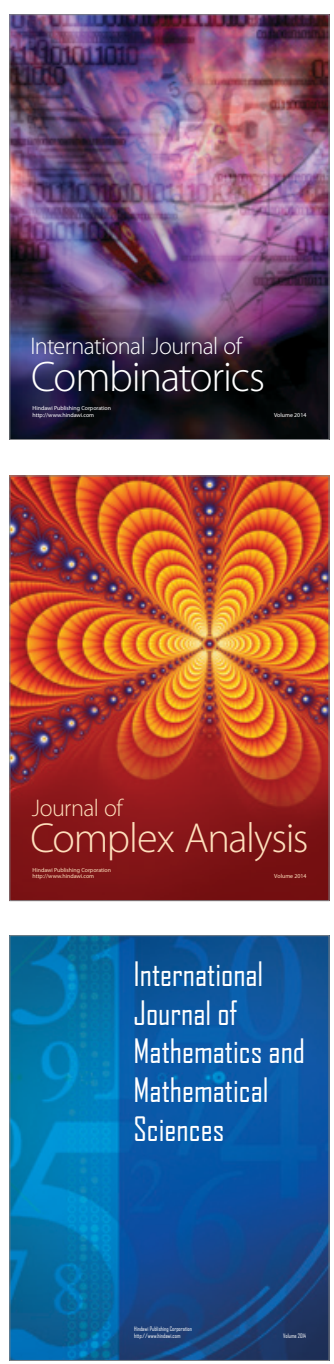
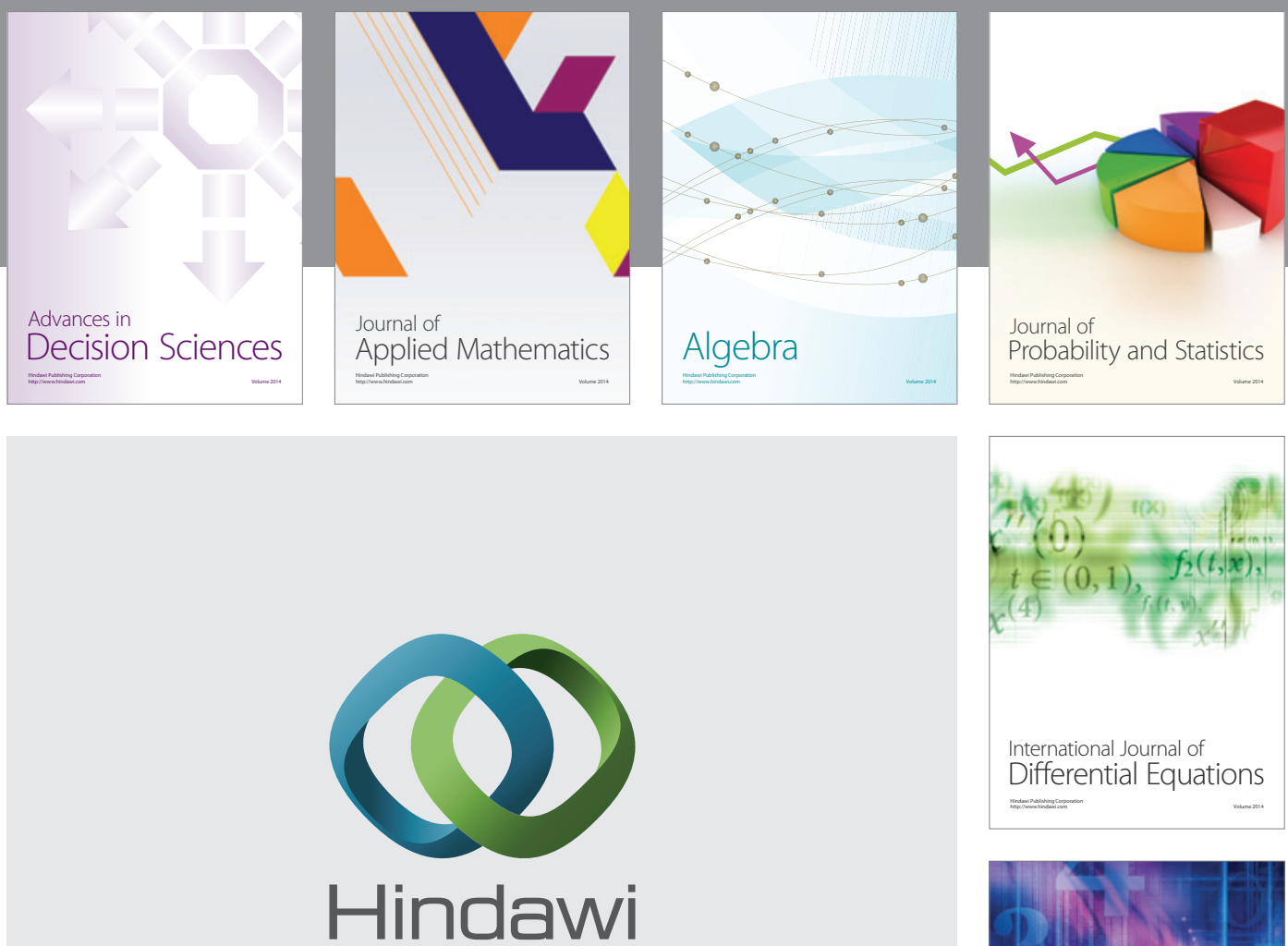

Submit your manuscripts at http://www.hindawi.com
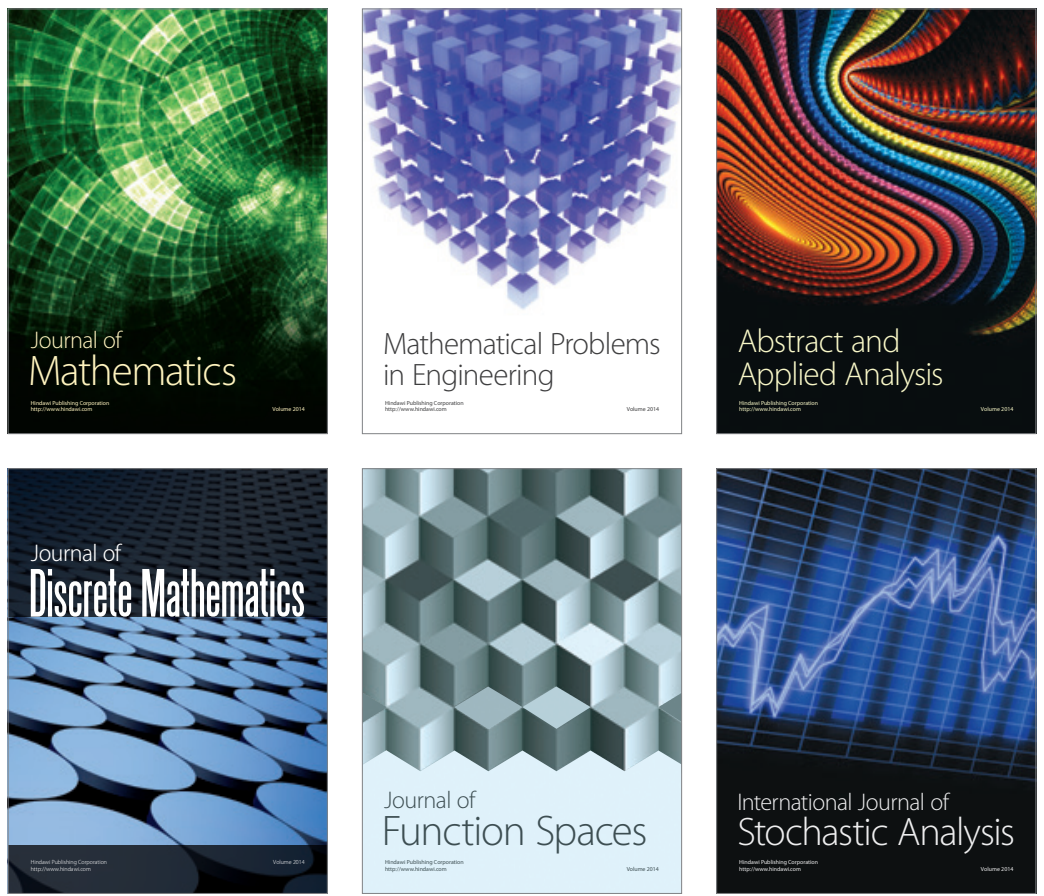

Journal of

Function Spaces

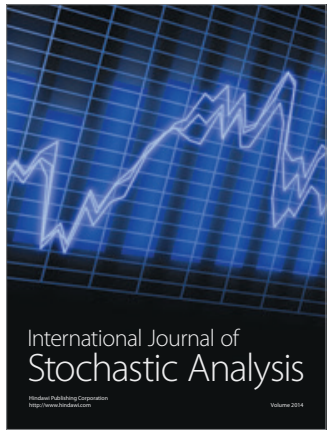

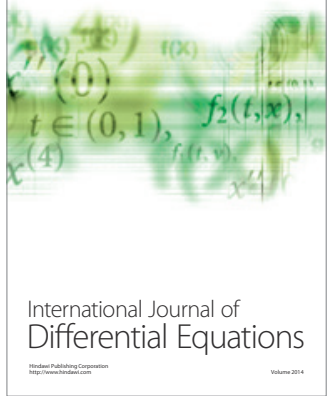
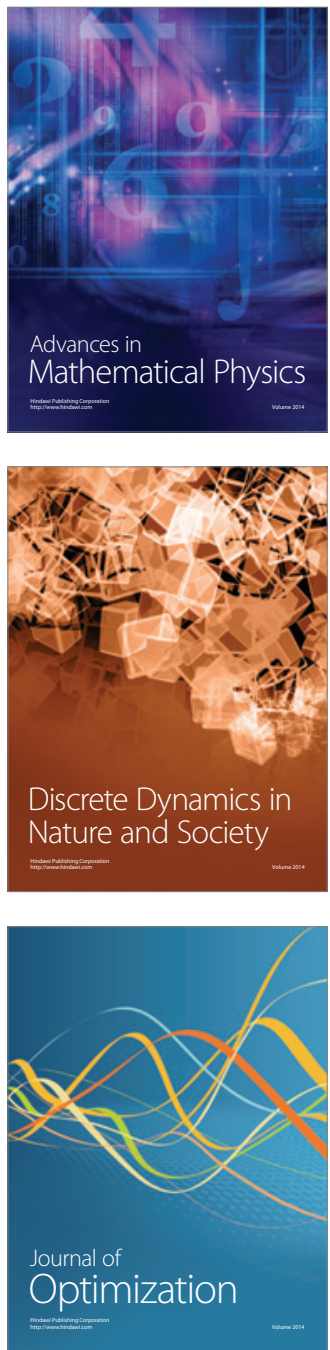